\title{
CAPACITY UTILIZATION AND MARKET POWER
}

\author{
Jean-François Fagnart, Omar Licandro and Henri Sneessens*
}

\begin{abstract}
In a monopolistic competition framework, we propose a dynamic model in which capacity underutilization is a macroeconomic equilibrium feature relying on a diversity of microeconomic situations. Capacity underutilization follows from microeconomic uncertainty at the time firms must decide on their productive capacity. We settle a relationship between capacity utilization and markups via the effect of capacity utilization rate changes on firms' market power. We show that such a relationship influences significantly the short run response of the economy to exogenous shocks. In particular, the same shock can have quite different short run effects depending on the characteristics of the initial stationary state (low or high capacity utilization rate).
\end{abstract}

Key Words

Capacity Utilization, Markups, Monopolistic Competition, Market Power

* J-F. Fagnart, University of Copenhagen and Université Catholique de Louvain. O. Licandro, FEDEA and Universidad Carlos III de Madrid. H. Sneessens, Université Catholique de Louvain and Université Catholique de Lille We thank Raouf Boucekkine for his most helpful advice on the numerical analysis of the model and Franck Portier and Joaquim Silvestre for their comments on an earlier version. We gratefully acknowledge the financial support of the Commission of the European Union (SPES-CT91-0079), the Spanish Ministerio de Educación y Ciencia (CE92-0017) and the Ministery of Scientific Research of the Belgian French Speaking Community (PAC 93/98-162) 



\section{Introduction}

The analysis of the determinants of factor utilization and markup rate variations is currently at the heart of several research programs in macroeconomics. It is now recognized that factor utilization and markup rate variations may play a crucial role in explaining business cycle fluctuations, either by contributing to generate endogenous fluctuations ${ }^{1}$ or by complexifying the economic mechanisms that propagate through the economy the effects of exogenous shocks. The literature on propagation mechanisms has usually discussed the effects of factor utilization and of markup rate changes separately. Factor utilization variability have received much attention in purely competitive real business cycle models as a mechanism which magnifies the effect of exogenous productivity shocks on the economy ${ }^{2}$. Several papers in the New-Keynesian literature have instead emphasized the effects of markup rate variations (especially counter-cyclical variations) as an important mechanism accouting for the propagation of exogenous demand shocks inside business cycle models with imperfect competition ${ }^{3}$. We emphasize in this paper the relationship between the two phenomena (factor utilization and markups) via the effect of capacity utilization rate changes on firms'market power in an imperfectly competitive economy. We show that such a relationship influences significantly the short run response of the economy to exogenous shocks.

The paper has two main objectives. The first objective is to provide an acceptable description of the microeconomics of capacity underutilization (such as heterogeneous utilization rates). In most existing intertemporal models with variable factor utilization, the capital utilization rate variable is introduced in the firm's intertemporal decision problem via its impact on capital depreciation ${ }^{4}$. The optimal capital utilization rate is such that

\footnotetext{
${ }^{1}$ See for instance the model developed in d'Aspremont, Dos Santos, Gerard-Varet (1994), where the variability of markup rates leads to the possibility of endogenous business cycles. Gali (1994) shows that self-fulfilling prophecies (sunspot fluctuations) are possible in presence of variable markups. In de la Croix and Licandro (1994), factor underutilization may be a source of endogenous fluctuations.

2Furthermore, when there are underutilization phenomena, the Solow residual can no longer be viewed as a measure of exogenous technological shocks. On labour hoarding, see e.g. Burnside, Eichenbaum and Rebelo, (1993)). On capacity utilization, see e.g. Greenwood, Hercovitz and Huffman (1988), Burnside and Eichenbaum (1994), Cooley, Hansen and Prescott (1994), Licandro and Puch (1995).

${ }^{3}$ See a.o. Rotemberg-Woodford (1991), (1992) and (1993), Portier (1995).

${ }^{4}$ Strictly speaking, those models do not really formalize the idea of capacity underutilization: there is simply a variation in the intensity of capital utilization. This issue is also raised by Cooley, Hansen and Prescott (1994) who focus instead on the concept of capacity idleness in way closer to ours.
} 
the marginal revenue induced by a more intensive use is offset by the marginal cost of faster capital depreciation. Although there may be such a link between capital utilization intensity and physical depreciation, we believe that it is unlikely to be the main driving force behind actual capacity utilization rate fluctuations, as reported in business surveys. For this reason, we propose a different representation, wherein capacity underutilization follows from microeconomic demand uncertainty and sluggish capacity adjustments. The model allows for microeconomic heterogeneity and implies an aggregate capacity utilization rate smaller than unity.

Our second objective is to stress the relationship between capacity utilization and market power in an imperfectly competitive goods market. In an imperfectly competitive setup, capacity constraints introduce a distinction between demand and sales price elasticities and for this reason influences optimal markup values. Capacity constraints therefore affect the propagation mechanism of exogenous disturbances in two ways. The first effect is similar to the effect that bottlenecks and stockouts have in a perfectly competitive setup; the second effect is related to imperfect competition and works through market power and optimal markup changes.

Constructing a model with such features in an intertemporal setup raises some difficulties. As we want a model where the diversity of situations across firms (and thus the heterogeneity of micro utilization rates) is recognized, we need explicit aggregation procedures which are unavoidably cumbersome. Noreover, modelling capacity constraints in an imperfect competition framework may become very complicated if the strategic dimension of the game played by firms is fully taken into account ${ }^{5}$. It is of course impossible to tackle all these issues at once within a full-fledged stochastic model. For this reason, we construct a non-stochastic ${ }^{6}$ model without important strategic dimension. We thus assume, as the macroeconomic literature usually does, an infinite number (a continuum) of imperfectly competitive firms. Our primary objective is to build a very simple model which remains sufficiently tractable to permit later developments or extensions. Our formulation is based on earlier work on macroeconomic models with capacity constraints and imperfectly competitive price setting (see Sneessens (1987), and subsequent works by a.o. Licandro (1995), de la Croix and Fagnart (1995)).

\footnotetext{
${ }^{5}$ See for example Kreps and Scheinkman (1983).

${ }^{6}$ More precisely, there is no aggregate uncertainty in the model. There are however idiosynchratic stochastic shocks.
} 
The key elements of our stylized intertemporal model can be briefly summarized as follows. The economy consists of a final and intermediate goods sector ${ }^{7}$. The firms in the intermediate goods sector are monopolistically competitive and must decide on the size of their productive capacity under uncertainty regarding the market demand for their output. In the (competitive) final good sector, independent technology shocks cause each intermediate good to have different marginal productivity. The demand for each intermediate good is thus different. This structure implies that the production of intermediate goods firm may be demand- or capacity-determined in function of the actual demand conditions. Accordingly, output levels, capacity utilization and markup rates thus differ across firms in function of these demand conditions. The average markup rate in the economy is positively linked to the average capacity utilization rate.

The paper is organized as follows. Section 2 is devoted to the description of individual behaviours. Section 3 characterizes the general equilibrium of this economy and analyzes the properties of its stationary state. Section 4 illustrates the dynamic properties of the model with two numerical examples which illustrate the interactions between capacity utilization and markup rates and their implications on the behaviour of other macroeconomic variables.

\section{Behaviours}

\subsection{Product firms}

The homogeneous final good is produced by a representative product firm. It is sold on a competitive market and can be used either as a consumption or an investment good. There is no fixed input, which implies that the optimization program of the representative firm remains purely static.

The production technology is represented by a constant return to scale CES production function defined over a continuum of variable inputs, each one denoted by $y$ and indexed by $j$, with $j$ belonging to the interval $[0,1]$. More formally, the representative product firm's output (denoted $Y$ ) is obtained from the following production function:

$$
Y_{t}=\left[\int_{0}^{1} v_{t}^{j \frac{1}{\theta}} y_{t}^{j \frac{\theta-1}{\theta}} \mathrm{d} j\right]^{\frac{\theta}{\theta-1}} \quad \text { with } \theta>1
$$

\footnotetext{
${ }^{7}$ Such a structure has been extensively used in the literature. See for instance Romer (1987), Farmer (1994), Gali and Zilibotti (1995).
} 
Each productivity parameter $v_{t}^{j} \geq 0$ is drawn from an i.i.d. stochastic process with unit mean and distribution function $\mathrm{F}(v)$.

Taking the final output price $P_{t}$ and the prices of the different inputs $\left\{P_{t}^{j}\right\}_{j}$ as given, the profit maximization of the firm at $t$ can then be written as:

$$
\max _{\left\{y_{t}^{j}\right\}_{j}, Y_{t}}\left[P_{t} Y_{t}-\int_{0}^{1} P_{t}^{j} y_{t}^{j} \mathrm{~d} j\right]
$$

subject to the technological constraint (1) where the parameters $\left\{v_{t}^{j}\right\}_{j}$ are known.

As the production technology displays constant returns-to-scale, the competitive firm always makes zero profits at the prevailing prices and is willing to produce any output level $Y_{t} \geq 0$.

For a given output level $Y_{t}$, the optimal demand of each input $j$ (i.e., the cost minimizing demand for $j$ ) is given by

$$
y_{t}^{j}=\left(\frac{P_{t}^{j}}{\mathcal{P}_{t}}\right)^{-\theta} Y_{t} v_{t}^{j}, \quad \forall j
$$

where the price index $\mathcal{P}_{t}$ of the inputs is defined as

$$
\mathcal{P}_{t}=\left[\int_{0}^{1}\left(P_{t}^{j}\right)^{1-\theta} v_{t}^{j} \mathrm{~d} j\right]^{\frac{1}{1-\theta}}
$$

The assumptions of perfect competition and constant-returns-to scale then imply $P_{t}=\mathcal{P}_{t}$.

For notational convenience, let $p_{t}^{j}$ be the relative price of input $j$ with respect to the price of the final good:

$$
p_{t}^{j}=\frac{P_{t}^{j}}{P_{t}}=\frac{P_{t}^{j}}{\mathcal{P}_{t}} .
$$

In the sequel, we use the final good as numeraire so that $P_{t}=\mathcal{P}_{t}=1$ for $t=1,2, \ldots$

\subsection{Input firms}

Each input $j$ is produced by a single firm (henceforth input firm). In order to obtain a simple concept of productive capacity, we assume that the production of each intermediate good combines labour and capital through a Leontief technology. The input firm's production capacity is predetermined and equal ${ }^{8}$ to the capital stock the firm installed in

\footnotetext{
${ }^{8}$ This assumption on the production technology allows us to build a very simple benchmark in which, at given capital stock, any fluctuation of output is only made possible by a variation of the capacity utilization rate. For notational convenience, we normalize capital productivity to 1 .
} 
period $t-1\left(k_{t-1}\right)$. Labour is supposed to be a purely variable input. It is bought on a competitive market and can be adjusted instantaneously to its optimal level. For a given production level $q_{t}^{j}$, the latter is given by

$$
\ell_{t}^{j}=\frac{q_{t}^{j}}{a_{t}}
$$

where $a_{t}$ represents the productivity of labour.

We assume that the capacity choice of firm $j$ for time period $t$ is made in $t-1$ and thus made under uncertainty regarding demand conditions (in particular, the realized values of the stochastic terms $\left\{v_{t}^{j}\right\}_{j}$ are still unknown). We examine successively the short run (i.e., at given productive capacity) optimization behaviour and the investment decision of the firm.

Short run decisions: Assuming that the price and output decisions take place after the realization of the idiosynchratic shocks $\left\{v_{t}^{j}\right\}_{j}$, the short run (real) profit maximization can be written as follows

$$
\max _{\left\{p_{t}^{j}, q_{t}^{j}\right\}}\left(p_{t}^{j}-\frac{w_{t}}{a_{t}}\right) q_{t}^{j}
$$

subject to the demand constraint (2) and the capacity constraint $q_{t}^{j} \leq k_{t-1}^{j}$.

Firm $j$ takes the wage level $w_{t}$, the final output level $Y_{t}$ and all the other prices as given. It is obvious that firm $j$ has always interest to eliminate any excess demand for its output by a rise in its price so that $q_{t}^{j}=y_{t}^{j}$. Associating the Lagrangean multiplier $\lambda_{t}^{j}(\geq 0)$ to the capacity constraint, the solution of the profit maximization is described as follows:

- Either $\lambda_{t}^{j}=0$ (the capacity constraint is not binding); firm $j$ then adopts the pricing rule $p_{1 t}^{j}$ which is given by a constant markup over the unit labour costs:

$$
p_{1 t}^{j}=\frac{\theta}{\theta-1} \frac{w_{t}}{a_{t}}
$$

and

$$
q_{t}^{j}=\left(p_{1 t}^{j}\right)^{-\theta} Y_{t} v_{t}^{j} \leq k_{t-1}^{j}
$$

- Or $\lambda_{t}^{j}>0$ (the pricing rule $p_{1 t}^{j}$ implies a demand level for $j$ larger than the productive capacity); firm $j$ then adopts the pricing rule $p_{2 t}^{j}$ which sets demand for $j$ at the level of the productive capacity, i.e.,

$$
q_{t}^{j}=\left(p_{2 t}^{j}\right)^{-\theta} Y_{t} v_{t}^{j}=k_{t-1}^{j}
$$


implying that

$$
p_{2 t}^{j}=\left[\frac{k_{t}^{j}}{Y_{t} v_{t}^{j}}\right]^{-1 / \theta}
$$

At given capacity, the latter pricing rule $p_{2 t}^{j}\left(>p_{1 t}^{j}\right)$ is increasing in $Y_{t} v_{t}^{j}$.

Let $\vec{v}_{t}^{j}$ represent the critical value of the demand parameter such that the demand for input $j$ at price $p_{1 t}^{j}$ is equal to the production capacity of supplier $j$, i.e.,

$$
\lambda_{t}^{j}\left\{\begin{array}{l}
=0 \text { if } v_{t}^{j} \leq \bar{v}_{t}^{j} \\
>0 \text { if } v_{t}^{j}>\bar{v}_{t}^{j}
\end{array}\right.
$$

It can be easily be shown that $\bar{v}_{t}^{j}$ is defined by

$$
\bar{v}_{t}^{j}=\frac{k_{t-1}^{j}}{\left(p_{1 t}^{j}\right)^{-\theta} Y_{t}}, \quad \forall j .
$$

For later use, it is also worth noting that the ratio of $p_{2 t}^{j}$ and $p_{1 t}^{j}$ can be expressed as a function of the ratio between the observed value of $v_{t}^{j}$ and the critical value $\bar{v}_{t}^{j}$ : from (9), one can indeed write that

$$
p_{2 t}^{j}=\left[\frac{v_{t}^{j}}{\bar{v}_{t}^{j}}\right]^{1 / \theta} p_{1 t}^{j}
$$

The investment decision of firm $j$ can then be represented by the following problem ${ }^{9}$ :

$$
\begin{gathered}
\max _{\left\{i_{t}^{j}\right\}_{t}} E \sum_{t=1}^{\infty} R_{t}\left\{\left(p_{t}^{j} q_{t}^{j}-\frac{w_{t}}{a_{t}} q_{t}^{j}\right)-i_{t}^{j}\right\} \\
\text { subject to } \quad k_{t}^{j}=(1-\delta) k_{t-1}^{j}+i_{t}^{j}, \quad \forall t \geq 1, \quad k_{0}^{j} \text { given } \\
\text { with } \quad R_{t}=\prod_{s=1}^{t}\left(1+r_{s}\right)^{-1}, \quad \forall t \geq 1
\end{gathered}
$$

The variable $r_{s}$ is the real interest rate ${ }^{10}$ at time period $s$ and $\delta$ is the depreciation rate of capital.

Before the realization of $v_{t}^{j}$, expected sales in $t$ are given by ${ }^{11}$

$$
\mathrm{E}\left(q_{t}^{j}\right)=\mathrm{E} \min \left\{y_{t}^{j}, q_{t}^{j}\right\}=\mathrm{E}\left(y_{t}^{j}\right) \int_{0}^{\bar{v}_{t}^{j}} v \mathrm{dF}(v)+k_{t-1}^{j} \int_{\bar{v}_{t}^{j}}^{\infty} \mathrm{dF}(v)
$$

\footnotetext{
${ }^{9}$ The investment goods are purchased in the final goods market. Their real price is thus equal to one.

${ }^{10}$ It may be worth repeating that there is no aggregate uncertainty in the economy so that the sequence of real interest rates can be perfectly anticipated.

${ }^{11}$ The expression $\mathrm{E}\left(X_{t}\right)$ denotes the expected value of the variable $X_{t}$ before observing the value of the parameter $v_{t}^{j}$.
} 


$$
\text { where } \mathrm{E}\left(y_{t}^{j}\right)=\left(p_{1 t}^{j}\right)^{-\theta} Y_{t}
$$

Similarly, the expected revenue associated to these sales is given by

$$
\mathrm{E}\left(p_{t}^{j} q_{t}^{j}\right)=p_{1 t}^{j} \mathrm{E}\left(y_{l}^{j}\right) \int_{0}^{\bar{v}_{t}^{j}} v \mathrm{dF}(v)+k_{t-1}^{j} \int_{\bar{v}_{t}^{j}}^{\infty} p_{2 t}^{j} \mathrm{dF}(v)
$$

One shows easily that the optimality condition for the capital stock to be installed in each period $t=1,2, \ldots$ is given by ${ }^{12}$

$$
r_{t+1}+\delta=\int_{\tilde{v}_{t+1}^{j}}^{\infty} \frac{\theta-1}{\theta} p_{2 t+1}^{j} \mathrm{dF}(v)-\frac{w_{t+1}}{a_{t+1}} \int_{\vec{v}_{t+1}^{j}}^{\infty} \mathrm{dF}(v)
$$

The latter optimality condition imposes that investment in every period be such that the marginal operating surplus expected from an additional unit of capital (right-hand side) be equal to the user cost of capital (left-hand side). The expected marginal operating surplus is equal to the profit margin per unit of output ${ }^{13}$ corrected by the probability of utilizing this extra unit of capital.

\subsection{Consumer}

In order to close the model, we consider an infinitely lived consumer whose intertemporal preferences with respect to consumption and labour are represented by a time separable utility function. The optimal time profiles of consumptions $\left\{C_{t}\right\}_{\{t=1, \ldots, \infty\}}$ and labour supplies $\left\{L_{t}\right\}_{\{t=1, \ldots, \infty\}}$ are given by the solution of the following problem:

$$
\max _{\left\{C_{t}, L_{t}\right\}} \sum_{t=1}^{\infty} \beta^{t} \mathcal{U}\left(C_{t}, L_{t}\right)
$$

subject to the wealth constraints

$$
A_{t}=A_{t-1}\left(1+r_{t}\right)+w_{t} L_{t}+\Pi_{t}-C_{t}-T_{t}, \quad \forall t \geq 1, \quad \text { with } A_{0} \text { given. }
$$

The $\mathcal{U}$ function is strictly increasing in $C_{t}\left(\mathcal{U}_{C}>0\right)$, decreasing in $L_{t}\left(\mathcal{U}_{L}<0\right)$, twice differentiable and strictly concave. The parameter $\beta$ is a constant subjective discount rate.

\footnotetext{
${ }^{12}$. Moreover, the discounted value of the capital stock which is available at $t$ must tend to zero when $t$ tends to infinity.

${ }^{13}$ A marginal unit of capital allows the firm to serve some extra demand when the capacity is binding but imposes a marginal reduction in prices (see the definition of $p_{2}^{j}$ in (8)): the corresponding extra revenue per unit of output is given by $(1-1 / \theta) p_{2}^{j}$. The marginal operating surplus per unit of output is then given by the latter term minus the unit labour cost.
} 
$A_{t}$ is the real financial wealth at $t . \Pi_{t}$ represents the monopolistic firms real profits. Since there is no aggregate uncertainty in the economy, the sequence of equilibrium profits, wages and rates of return $\left\{w_{t}, r_{t}\right\}_{\{t=1, \ldots, \infty\}}$ is perfectly foreseen by the consumer. The sequence of lump-sum taxes $\left\{T_{t}\right\}_{\{t=1, \ldots, \infty\}}$ (financing the government spending) is taken as given by the consumer.

Optimal consumption demand and labour supply profiles satisfy the following first-order conditions at any time $t \geq 1$

$$
\begin{aligned}
\mathcal{U}_{C}\left(C_{t}, L_{t}\right) & =\mathcal{U}_{C}\left(C_{t+1}, L_{t+1}\right) \beta\left(1+r_{t+1}\right) \\
w_{t} \mathcal{U}_{C}\left(C_{t}, L_{t}\right) & =-\mathcal{U}_{L}\left(C_{t}, L_{t}\right) .
\end{aligned}
$$

Moreover, the consumption and labour supply profiles must satisfy the intertemporal budget constraint of the agent. This is equivalent to saying that

$$
\lim _{t \rightarrow \infty} R_{t} A_{t} \geq 0,
$$

which must be satisfied with strict equality if there is no satiation.

The interpretation of the standard conditions (15) and (16) is fairly straightforward.

\section{General Equilibrium}

\subsection{Equilibrium and Aggregation in the Inputs Sector}

At the time they make their capacity choice, all the input firms $j$ have the same information about their individual demand and face exactly the same uncertainty. Assuming that all firms have the same initial capital stock $\left(k_{0}^{j}=k_{0}, \forall j\right)$, they will choose the same capital stock in each period:

$$
k_{t}^{j}=k_{t}, \quad \forall j, \forall t \geq 1
$$

As all firms then have the same productive capacity, the critical value for the demand parameter $\bar{v}_{t}^{j}$ is the same for all (and $p_{1 t}^{j}=p_{1 t}$ ):

$$
\forall j \in[0,1], \quad \bar{v}_{t}^{j}=\bar{v}_{t}=\frac{k_{t}}{Y_{t}} p_{1 t}^{\theta}
$$

However, as different input firms experience different demand shocks, individual optimal 
price and output decisions differ across firms:

$$
\left\{\begin{array}{l}
\text { if } v_{t}^{j} \leq \bar{v}_{t}, \text { then } p_{t}^{j}=p_{1 t} \text { and } q_{t}^{j}=y_{t}^{j} \leq k_{t-1} \\
\text { if } v_{t}^{j}>\bar{v}_{t}, \text { then } p_{t}^{j}=p_{2 t}^{j} \text { and } q_{t}^{j}=k_{t-1}
\end{array}\right.
$$

where $p_{2 t}^{j}$ is given by (8) and $y_{t}^{j}$ is given by (2).

$F\left(\bar{v}_{t}\right)$ represents the proportion of firms that have idle capacities (i.e., those for which $\left.v_{t}^{j} \in\left[0, \bar{v}_{t}\right]\right) ; 1-\mathrm{F}\left(\bar{v}_{t}\right)$ is the proportion of firms at full capacity.

From (18) and the definition of the aggregate price index (see (3)), we obtain after normalization the following relationship between $p_{1 t}$ and $p_{2 t}$ :

$$
1=\int_{0}^{\bar{v}_{t}} p_{1 t}^{1-\theta} v \mathrm{dF}(v)+\int_{\bar{v}_{t}}^{\infty} p_{2 t}^{1-\theta} v \mathrm{dF}(v)
$$

Alternatively, by using (10),

$$
p_{1 t}=\left[\int_{0}^{\bar{v}_{t}} v \mathrm{dF}(v)+\bar{v}_{t} \int_{\bar{v}_{t}}^{\infty}\left(\frac{v}{\bar{v}_{t}}\right)^{1 / \theta} \mathrm{dF}(v)\right]^{\frac{1}{\theta-1}} \leq 1
$$

Since, for each firm, $p_{2 t}$ is larger than $p_{1 t}$, it is obvious that that $p_{1 t}$ is always smaller than 1. In the extreme case where no capacity constraint is binding (i.e., $\bar{v}_{t} \rightarrow \infty$ ), equation (20) gives the standard result that $p_{1 t}=1$ in an equilibrium that becomes symmetric in prices. At the other extreme, when $\bar{v}_{t}$ is equal to zero (no idle capacities left), equation (19) then serves to determine the full capacity output (see equation (23) below).

Given the employment level in each firm, aggregate employment, denoted $L_{t}$, is given by:

$$
L_{t}=\frac{1}{a_{t}}\left\{\left(p_{1 t}\right)^{-\theta} Y_{t} \int_{0}^{\bar{v}_{t}} v \mathrm{dF}(v)+k_{t-1} \int_{\bar{v}_{t}}^{\infty} \mathrm{dF}(v)\right\}
$$

\subsection{Dynamic General Equilibrium}

Given the features of an equilibrium in the inputs market, a dynamic general equilibrium of the economy is a sequence of prices $\left.\left\{p_{t}^{j}\right\}_{j}, w_{t}, r_{t}\right\}_{t}$ and a sequence of quantity variables $\left\{\left\{c_{t}^{j}, \ell_{t}^{j}\right\}_{j}, k_{t}, C_{t}, L_{t}\right\}_{t}$ such that at each time period $t=1,2, \ldots$

- $\left\{p_{t}^{j}\right\}_{j}$ and $\left\{q_{t}^{j}, \ell_{t}^{j}\right\}_{j}$ satisfy (18) and (4) for all $j$

- the labour market (characterized by equations (16) for supply and (21) for demand) clears. 
- the final output level is given by

$$
Y_{t}=C_{t}+k_{t}-(1-\delta) k_{t-1}+G_{t}
$$

where the optimal consumption level is derived from equation (2) and the optimal capital stock is given by (13), with $k_{0}$ given.

\subsection{Capacity utilization and markups}

Let $Y_{t}^{*}$ be the full capacity final output in the economy. Since productive capacities are predetermined, $Y_{t}^{*}$ is simply given by (see (1))

$$
Y_{t}^{*}=k_{t-1}\left(s_{\theta}\right)^{\frac{\theta}{\theta-1}} \quad \text { where } \quad s_{\theta}=\int_{0}^{\infty} v^{1 / \theta} \mathrm{dF}(v)=\int_{0}^{1}\left(v_{t}^{j}\right)^{1 / \theta} \mathrm{d} j
$$

$s_{\theta}$ represents an aggregation constant.

Let $D_{t}$ be the capacity utilization rate at the aggregate economy level:

$$
D_{t}=\frac{Y_{t}}{Y_{t}^{*}}
$$

where $D_{t}$ is strictly smaller than 1 as long as there remain idle capacities in some firms, i.e., as long as $F\left(\bar{v}_{t}\right)$ remains different ${ }^{14}$ from 0 . The instantaneous correlation between output and capacity utilization is necessarily positive. In other words, the aggregate capacity utilization rate depends negatively on $\bar{v}_{t}$, i.e., on the proportion of firms the output of which is demand determined. As the latter firms have a lower markup rate, there exists an increasing relationship between the capacity utilization rate $D_{t}$ and the average markup rate across firms. Indeed, a decrease in $\bar{v}_{t}$, say $\Delta \bar{v}_{t}$, means that $\mathrm{f}\left(\bar{v}_{t}\right) \Delta \bar{v}_{t}$ extra firms are now at full capacity and switch from the pricing rule $p_{1}$ to the pricing rule $p_{2}$. At given price elasticity of demand, this implies an increasing relationship between capacity utilization and average markup rate. Analytically, dividing the input price index (see (19)) by unit labour costs $\left(w_{t} / a_{t}\right)$ allows us to compute the average markup rate $\mu_{t}$ over marginal costs:

$$
\mu_{t}=\frac{\theta}{\theta-1} \frac{1}{p_{1 t}}
$$

\footnotetext{
${ }^{14}$ Strictly speaking, full capacity utilization occurs when $\bar{v}_{t}=0$. However, as we outline in the sequel, the economy may be de facto in an equilibrium with full utilization even though $\bar{v}_{t} \neq 0$. If the variance of the idiosynchratic shocks is small enough, a strictly positive value of $\bar{v}_{t}$ may indeed be consistent with the fact that the proportion of firms with idle capacities $F\left(\bar{v}_{t}\right)$ is not different from zero. If $\bar{v}_{t}$ was exactly equal to zero, the general equilibrium would still be characterized by the same set of equations as before except that equation (19) would then collapse into (23), the labour demand then being equal to $k_{t-1} / a_{t}$.
} 
Given (20), $\mu_{t}$ is a decreasing function of $\bar{v}_{t}$, bounded below by $\theta /(\theta-1)$. When no capacity constraint is binding, $p_{1 t}$ is equal to 1 and $\mu_{t}$ is the standard function of the (here constant) price elasticity of demand. The larger the number of firms at full capacity (i.e., the more $p_{1 t}$ departs from its upper bound 1), the higher the average markup rate in the economy.

\subsection{Stationary State Equilibrium}

At the stationary state, $\left\langle a_{t}, T_{t}, G_{t}\right\rangle=\langle a, T, G\rangle$ and each endogenous variable remains constant. Equation (15) then determines the stationary interest rate as a function of the subjective time discount rate:

$$
r=\frac{1-\beta}{\beta} .
$$

Provided that $\bar{v}$ is strictly positive, we know (see 20) that the relative price $p_{1}$ can be written as a monotonic function of $\bar{v}$, i.e., suppressing the time index $t$,

$$
p_{1}=\left[\int_{0}^{\bar{v}} v \mathrm{dF}(v)+\bar{v} \int_{\bar{v}}^{\infty}\left(\frac{v}{\bar{v}}\right)^{1 / \theta} \mathrm{dF}(v)\right]^{\frac{1}{\theta-1}}
$$

where $p_{1}$ goes to 1 (resp. 0 ) when $\bar{v}$ goes to $\infty$ (resp. 0 ).

From the optimal investment rule (13) and after suppressing the time indices and replacing the relative price $p_{2}$ and the real unit labour cost $w / a$ by their expressions in terms of $p_{1}$ (see equations (10) and (5)), we obtain another monotonically increasing relationship between $p_{1}$ and $\bar{v}$ which holds for any strictly positive value of $\bar{v}$ :

$$
p_{1}=(r+\delta) \frac{\theta}{\theta-1}\left[\int_{\bar{v}}^{\infty}\left(\frac{v}{\bar{v}}\right)^{1 / \theta} \mathrm{dF}(v)-\int_{\bar{v}}^{\infty} \mathrm{dF}(v)\right]^{-1}
$$

where $p_{1}$ tends to $\infty$ (resp. 0 ) when $\bar{v}$ tends to $\infty$ (resp. 0 ).

The stationary state equilibrium values of $\bar{v}$ and $p$ are determined by the intersection of (25) and (26). Given the monotoniticy of the two relationships and their behaviour at the two limit values of $\bar{v}$, a sufficient condition for the existence of such an intersection at a strictly positive value of $\vec{v}$ is that the slope of (25) be strictly larger than the slope of 
(26) when $\bar{v}$ tends to zero. One can show that this will be the case if ${ }^{15}$

$$
s_{\theta}>\left[(r+\delta) \frac{\theta}{\theta-1}\right]^{\frac{\theta-1}{\theta}} .
$$

If (27) is not satisfied, the stationary state equilibrium is then characterized by the full utilization of production capacities and $\bar{v}=0$. Equation (25) then collapses into $Y=Y^{*}$ (see (23)), whereas the analytical manipulations which lead to (26) now determine the stationary level of real wages.

The stationary values of all the other variables can next be determined. Because of the constant returns to scale assumption, the stationary state values of the variables $\tilde{v}, p_{1}, w$ will not depend on the consumer's intratemporal preferences $\mathcal{U}$ which only influence the stationary levels of output, employment, consumption and capital stock.

\subsection{Implications for short run dynamics}

We propose hereafter a diagrammatical representation of the labour market equilibrium at given capital stock and at the stationary state. In the two panels of figure 1, the upward-sloping curve represents a standard labour supply curve as implied by equation (16). The other curve (sloping downwards in figure 1.a, horizontal in figure 1.b) represents the macroeconomic labour demand curve given by equation (21) (combined with equations (17) and (20)). From the previous section, the stationary state wage level is known to be independent of the employment level, so that the long-term labour demand curve is horizontal (figure 1.b). In the very short run, i.e, at given capital stock, the labour demand curve is sloping downwards and intersects the two axes. It necessarily intersects the horizontal axis because, even at zero wage, the short run demand for labour is bounded above by the number of available job slots corresponding to the full employment of the installed capacities (i.e., from equation (21) in that case, $L_{t}=k_{t-1} / a_{t}$ ). Given the labour demand equation, the employment level is linked positively to the capacity utilization rate. In other words, $\bar{v}_{t}$ varies along a short run labour demand schedule so that the aggregate capacity utilization rate and the average markup also vary. A downwards shift

\footnotetext{
${ }^{15}$ For instance, if $\left\{v^{j}\right\}_{j}$ are lognormally distributed, $s_{\theta}$ is bounded above by 1 and the condition should be satisfied for plausible values of $r$ and $\delta$, unless $\theta$ is so close to 1 that the right-hand-side of (27) is larger than 1. For example, if $r+\delta$ is equal to 0.2 (what is unrealiscally high on a quaterly basis), (27) is satisfied if $\theta \geq 1.45$ when $\sigma_{v}^{2}=0.75$, if $\theta \geq 1.3$ when $\sigma_{v}^{2}=0.2$. It goes without saying that for lower (and more realistic) values of $r+\delta,(27)$ remains satisfied for lower values of $\theta$.
} 
along this curve corresponds to an increase in the proportion of firms that produce at full capacity and therefore to an increase in the markup rate. When $L$ is small (in particular when it goes to zero), all firms underutilise their production capacity and $p_{1 t}=1$. The feasible real wage (as implied by $(17)$ ) is then equal to $(1-1 / \theta) a$. It should be noticed

Figure 1: Instantaneous and stationary equilibria in the labour market

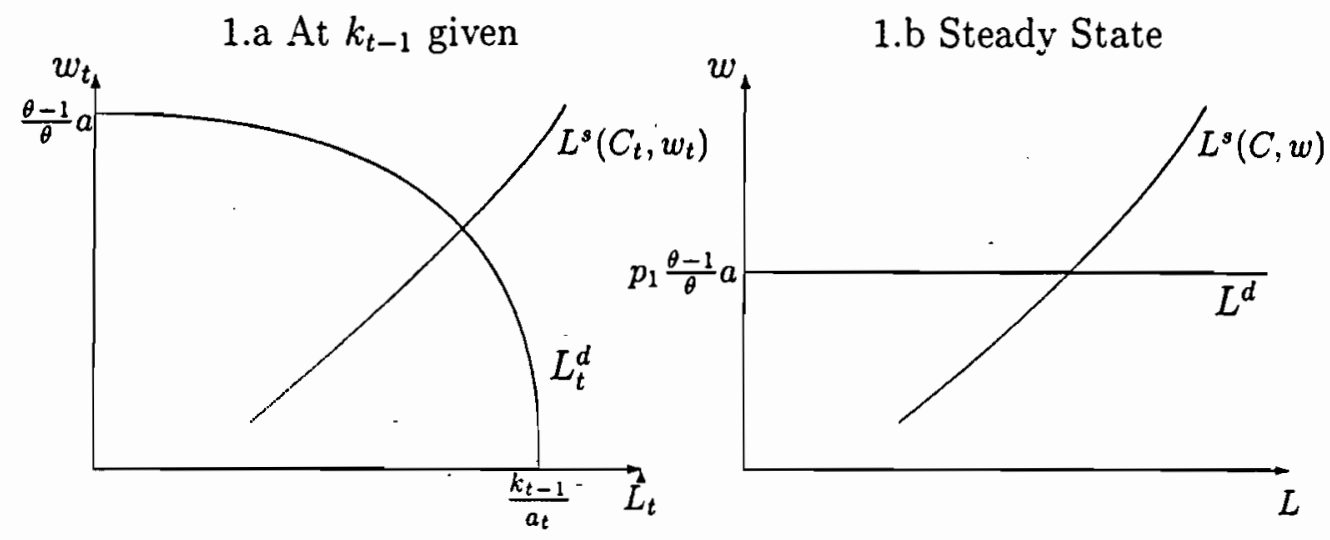

that the labour demand curve may be vertical (i.e., have an infinite slope for an interval of values of the real wage) at the level of the maximum employment level ${ }^{16}$. As we have explained in the previous section, the economy exhibits de facto full utilisation for all the values of $\bar{v}_{t}$ such that $\mathrm{F}\left(\bar{v}_{t}\right)$ is null. A downwards move along the vertical part of the curve then implies that markups rise while real wages decrease (at unchanged employment and output levels).

In a simple way, the above diagrammatical representation illustrates the interactions between capacity utilization and markup variations and the other variables in the short run. In particular, it shows clearly why the short run effects of a same perturbation depends crucially on the value of the capacity utilisation rate when the perturbation occurs. Consider an economy initially at its stationary state as described in figure 1.b. A pertubation occurs. Instantaneously, the economy is now characterized by figure 1.a. Depending on the initial capacity utilization rate, the economy lies in a given point of the short run labour demand curve. If it lies in the flatter part of the curve (low utilization rates), firms respond to the perturbation by changing their production plan with little change in markups and prices. If, to the contrary, the utilization rates are high (steeper

\footnotetext{
${ }^{16}$ In the same way, it should also be pointed out that the labour demand curve is horizontal over an interval of employment levels close to zero. The highest feasible wage is indeed reached when all firms have idle capacities. The zero employment level is only the most extreme case of such a situation.
} 
part of the curve), firms will raise their markups and there will be little output effect in the short run.

\section{Transitional Dynamics and Numerical Simulations}

This section has two objectives. The first one is simply to check the local stability of the model. We solve this nonlinear model by using a Newton-Raphson relaxation method proposed by Laffargue (1990) and further developed by Boucekkine (1995). As Boucekkine shows, Laffargue's algorithm is very powerful to check the existence of a unique stable saddle-point solution. Indeed, non saddlepoint models induce an explosive behavior of Laffargue's algorithm ${ }^{17}$ and are thus ill-conditioned. This algorithm thus allows ones to check the existence and the uniqueness of the saddlepoint solution in a very convenient way.

The second objective of the section is to illustrate the interactions between capacity utilization and markup rates and the other variables by analysing numerically the dynamic behavior of the model in response to various changes in the environment of firms. This will allow us to illustrate that a same shock can have quite different short run effects depending on the characteristics of the initial steady state ("low" or "high" capacity utilization rate).

We consider two economies which are identical except for the variance $\sigma_{v}^{2}$ of the idyosynchratic shocks $\left\{v^{j}\right\}_{j}$. The main difference between the stationary equilibria of these two economies is the value of the equilibrium capacity utilisation rate, which is higher the lower ${ }^{18}$ the variance $\sigma_{v}^{2}$. $F(v)$ is assumed a lognormal distribution function. In the first economy (called hereafter the Unitary $D$ economy), we set $\sigma_{v}^{2}$ to 0.00005 so as to produce an equilibrium very close to full capacity utilisation. In the second economy (called hereafter the Low $D$ economy), we set $\sigma_{v}^{2}$ to 0.2 implying a capacity utilization rate of about $86 \%$ given the other parameters of the model.

\footnotetext{
${ }^{17}$ This explosive behavior in presence of a non saddlepoint model is induced by a simple numerical test which relies on the initialization of the algorithm. If the algorithm is initialized with values of the endogenous variables which depart sligthly from the stationary state values, an explosive behavior appears at the first Newton-Raphson iteration when the simulation horizon tends to infinity (i.e., in the numerical experiment, when the simulation horizon becomes large).

${ }^{18}$ Indeed, the larger $\sigma_{v}^{2}$, the larger the mismatch between demands and supplies, and consequently the lower $D_{t}$ at any productive capacity level.
} 
For these other parameters, we choose the following calibration. We assume a utility function of the CRRA variety like

$$
\mathcal{U}\left(C_{t}, L_{t}\right)=\frac{C_{t}^{1-\gamma}}{1-\gamma}-\frac{L_{t}^{1+\tau}}{1+\tau}
$$

with $\gamma=1.2$ and $\tau=1$ and choose the following values for the other parameters of the model: $a=1, \theta=4$ (which implies a mark-up rate of about $40 \%$ in the model), $\beta=0.99$ (so that the real interest rate on a quaterly basis is about $1 \%$ ), $G=0, \delta=0.0188$.

The values of the most important variables at the stationary state in these two economies are given in the following table:

\begin{tabular}{c|cccccc} 
& $\bar{v}$ & $\mathrm{~F}(\bar{v})$ & $D$ & $\mu$ & $Y$ & $C$ \\
\hline Unitary $D\left(\sigma_{v}^{2}=0.0000 \overline{)}\right)$ & 0.855 & $\approx 0$ & $\approx 1$ & 1.387 & 0.871 & 0.854 \\
Low $D\left(\sigma_{v}^{2}=0.2\right)$ & 0.944 & 0.531 & 0.866 & 1.410 & 0.862 & 0.843
\end{tabular}.

We analyse successively the effects of a temporary and a permanent shock. The temporary shock increase in governement spendings $G$. The permanent one represents a labour augmenting technical progress (increase in the productivity coefficient $a$ ). For the two economies (Unitary $D$ and Low $D$ ), we report the time profiles of ouput, capacity utilization rate, employment, markup rate, consumption and real wage rate. (see figures 2 and 4). In each of these figures, the vertical axis measures the gap (in \%) between the value of the variable at time $t$ and its value at the initial stationary state.

\section{a) Temporary Increase in Government Purchases}

We suppose a temporary increase in $G$. The initial impulse $G_{1}$ is equal to $1 \%$ of the stationary level of output and has not been anticipated by the agents. In the following periods ( $t>1), G_{t}$ is given by $G_{t}=0.95 G_{t-1}$ and perfectly anticipated. The purpose of this numerical exercice should not be misunderstood. In absence of capacity constraints, markups would be constant in our economy. It is therefore obvious that the governement spending shock cannot be magnified. The existence of capacity constraints tends to dampen it instead. Our point is precisely to show how the initial capacity utilization rate influences the response of the economy to the shock.

In figure 1 above, an increase in $G$ leaves the labour demand curves unaffected and only shifts the labour supply curve to the right (negative wealth effect) implying a downwards 
move along the short run labour demand curve. An instantaneous (and positive) effect on output is only possible in an economy with capacity underutilization, i.e., as long as the labour demand curve has a finite slope. The instantaneous effect in the unitary $D$ economy (vertical demand curve) is necessarily null.

As figure 2 shows clearly: the short run effects (up to 5 periods) of the gouvernement spending increase are much more expansionary in the Low $D$ economy than in the Unitary $D$ one. A difference between the evolution of the markup and real wage rates in the two economies is striking: the government spending increase raises very significantly the markup rate in the unitary $D$ economy, leading to much more depressed real wages.

\section{b) Labour Augmenting Technical Progress $a$.}

We now consider a permanent and deterministic increase of $1 \%$ in the productivity of labour.

The long run effects of such a technical progress are clear. It increases the real wage by $1 \%$ (upwards shift of the stationary state labour demand curve in figure 1), raises the stationary levels of output, consumption and capital. The stationary effect on employment remains ambiguous and depends on the parameters characterizing the utility function (and determining the size of the shift of the labour supply curve to the left). In the short run, the increase in the productivity of labour reduces the maximum employment level (less workers are now necessary for a given production capacity) but increases the maximum wage level. The short run labour demand curve thus moves upwards at low levels of employment and inwards near the maximum employment level (see figure 3 below).

The instantaneous effects of the productivity gain thus depend crucially on whether the initial employment level is to the left or to the right of the intersection point between the old and the new demand curves, i.e., on whether the initial equilibrium capacity utilization rate is small (flatter part of the labour demand curve) or large (steeper part of the labour demand curve). In the first case, the productivity gain induces an instantaneous rise in real wages while the effect on employment remains ambiguous and depends on the labour supply behavior. In the second case, the instantaneous effect on employment is negative; the size of the employment contraction determines whether the short run real wage falls or increases.

In the two numerical exercices, the long run employment level is lower after the increase 
Figure 2: Impulse response to a temporary government spending increase
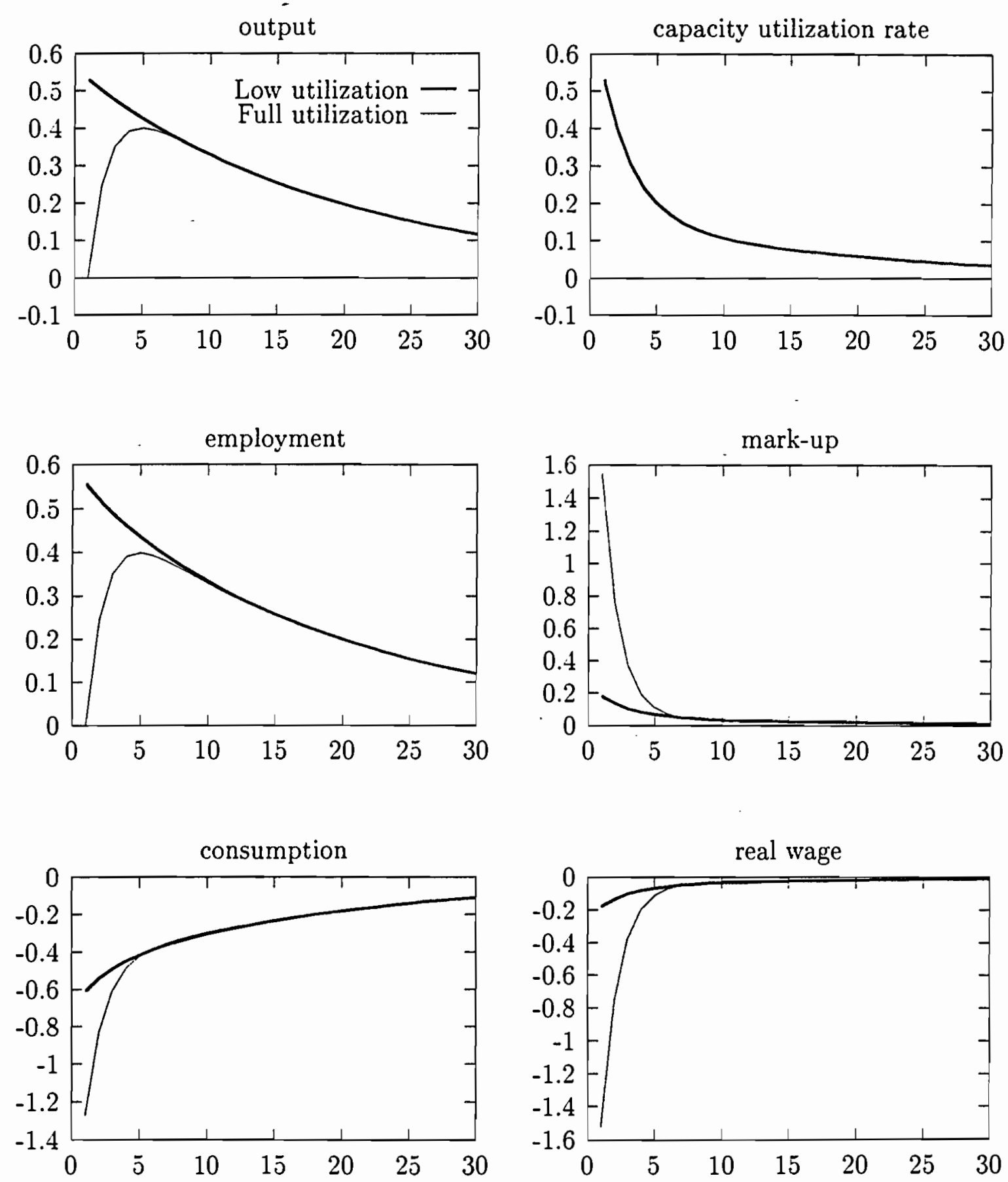
Figure 3: Effects of a labour productivity gain
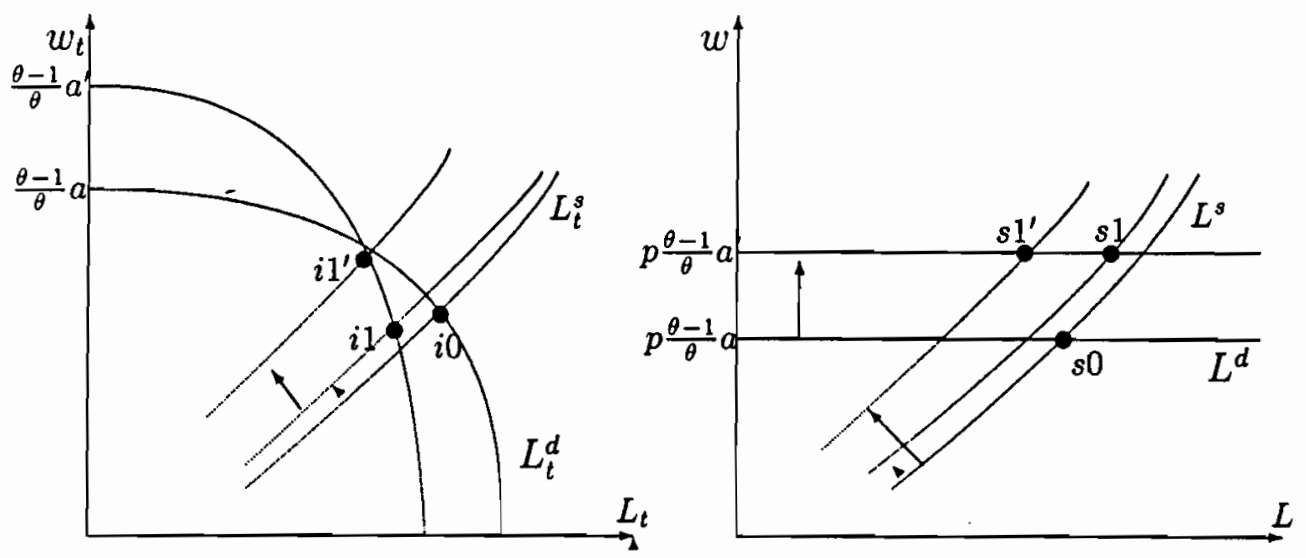

in the labour productivity and the employment level falls instantaneously. It even falls below its new stationary value in the unitary $D$ economy. At given capital productivity, the labour productivity gain leads to a short run increase in capacity utilization in the low $D$ economy where the employment contraction is consequently less severe. Again, the unitary $D$ economy exhibits a stronger variability of markups so that the labour market clearing requires much stronger fluctuations in real wages. Moreover, since most firms in the Low $D$ economy are able to easily respond to extra demand for goods, production goes to its new stationary state level more quickly than in the Unitary $D$ economy.

\section{Conclusions}

By introducing microeconomic demand uncertainty in a dynamic intertemporal setup with imperfect competition, we have developped a theoretical model wherein capacity underutilization -following from demand uncertainty- is a macroeconomic equilibrium feature relying on a diversity of microeconomic situations. We have shown that capacity utilization and markup rate changes are related via the effect of the former on the firm's actual market power. This relationship between capacity utilization and markups has strong implications on the way exogenous stochastic shocks can propagate through the economy. The same shock can have quite different effects depending on the characteristics of the initial stationary state (low or high capacity utilization rate). In case of a permanent shock, the initial capacity utilization rate also influences the time the economy nceds to approach its new stationary state. 
Figure 4: Impulse response to a labor productivity increase
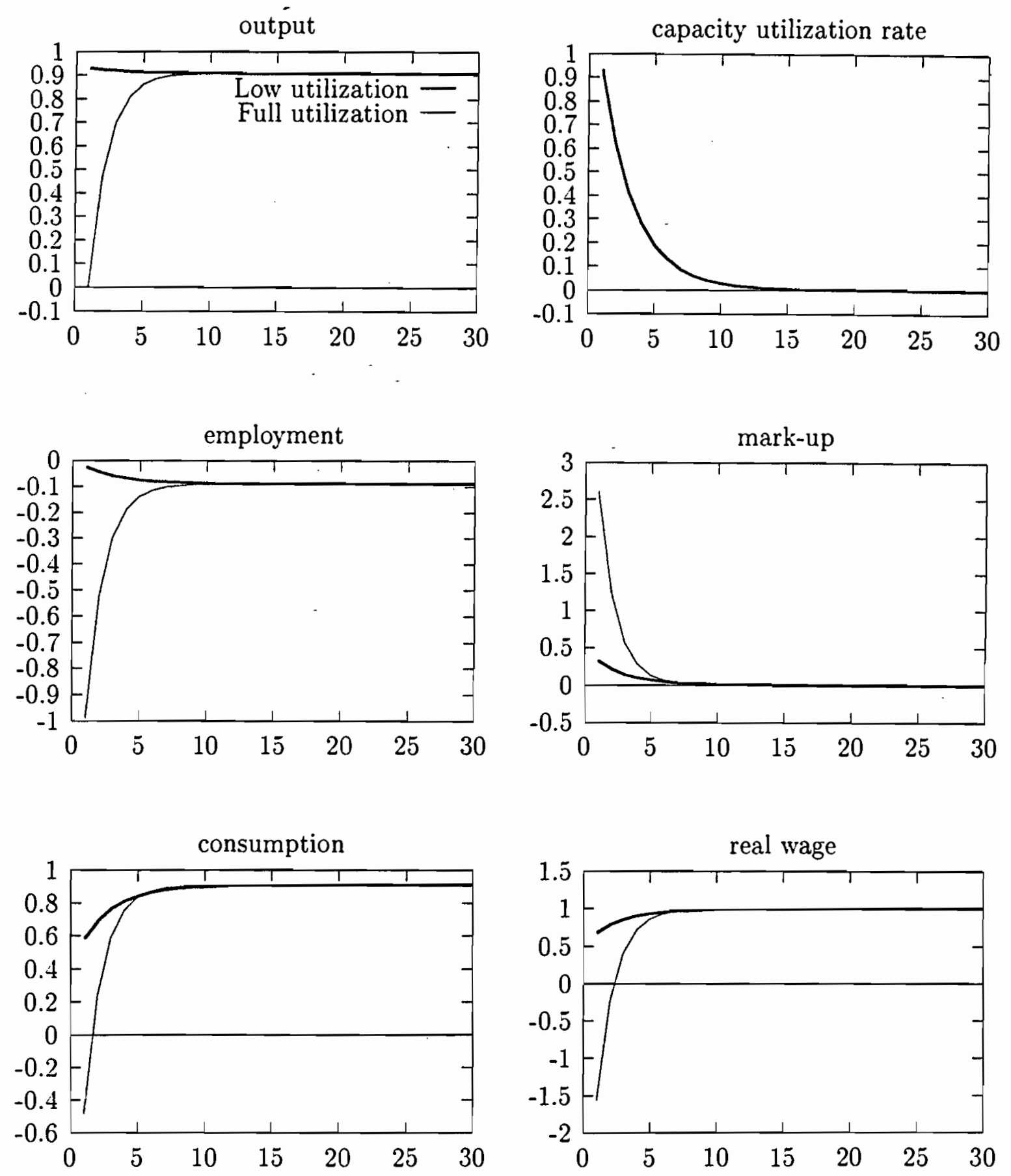
We should emphasize in this context that the positive relationship between capacity utilization and markup rates does not imply per se a positive correlation between output and markup rates over the cycle. The latter correlation can be positive or negative, and depends on the correlation between productive capacities and output. Moreover, any source of variability in the price elasticity of demand itself is likely to complexify significantly the relationship existing between capacity utilization and market power.

The model presented in this paper can be used as a starting point for further developments. The next logical step is of course to complete the model with stochastic processes and to examine the characteristics of the cyclical fluctuations so generated. We leave this topic for future research.

\section{References}

d'Aspremont C., L-A. Gerard-Varet, R. Dos Santos Ferreira (1994), "Market Power, Coordination Failures and Endogeneous Fluctuations", CORE Discussion Paper n 9468.

Boucekkine R. (1995), "An Alternative Methodology for Solving Nonlinear ForwardLooking Models", The Journal of Economic Dynamics and Control, 19, 711-734.

Burnside C., M.Eichenbaum and S.Rebelo (1993), "Labor Hoarding and the Business Cycle", Journal of Political Economy, Vol. 101, (April), 245-2خ3.

Burnside C. and M.Eichenbaum (1994), "Factor Hoarding and the Propagation of Business Cycle Shocks", NBER Working Paper ìo 4675.

Cooley T., G. Hansen and E. Prescott (1994), "Equilibrium Business Cycles with Idle Resources and Variable Capacity Utilization", Fed. Reserve Bank of Minneapolis, WP 535 .

de la Croix D. and J-F.Fagnart (1995), "Lnderemployment of Production Factors in a Forward-looking Model", Labour Economics, 2, 131-159.

de la Croix D. and O.Licandro (1994), "Irreversibility, Uncertainty and Underemployment Equilibria", mimeo IRES, Université Catholique de Louvain $n^{\circ} 9428$.

Dixit A. and J.Stiglitz (1977), "Monopolistic competition and Product Diversity", American Economic Review, 67(3), 297-308. 
Farmer R. (1993), The Macroeconomics of Self-Fulfilling Prophecies, Cambridge, MA: The MIT Press.

Gali J. (1994), "Monopolistic Competition, Business Cycle and the Composition of Aggregate Demand", Journal of Economic Theory.

Gali J. and F. Zilibotti (1995), "Endogenous Growth and Poverty Traps in a Cournotian Model", Annales d'Economie et de Statistique, 37/38, 197-214.

Greenwood J., Z.Hercowitz and G. Huffman (1988) "Investment, Capacity Utilization and the Real Business Cycle", American Economic Review, Vol. 78, (June), 402-417.

Kreps D. and J. Scheinkman (1983), "Quantity Pre-Commmitment and Bertrand Competition Yield Cournot Outcomes", Bell Journal of Economics, 14, 326-337.

Laffargue J-P. (1990), "Résolution d'un modèle macroéconomique à anticipations rationnelles", Annales d'Economie et de Statistique, 17, 97-119.

Licandro O. (1995), "A Non-Walrasian General Equilibrium Model with Monopolistic Competition and Wage Bargaining", Annales d'Economie et de Statistique, 37/38, 237254.

Licandro O. and L. Puch (1995), "Capital Utilization, Maintenance Costs and the Business Cycle." WP 95-34, Universidad Carlos III de Madrid.

Romer P. (1987), "Growth Based on Increasing Returns Due to Specialization", American Economic Review, 77(2), 56-62.

Rotemberg J. and M. Woodford (1991), "Markups and the Business Cycle", NBER Macroeconomics Annual, O.J. Blanchard and S. Fisher eds., Cambridgge, MA: MIT Press, 63-128.

Rotemberg J. and M. Woodford (1992), "Oligopolistic Pricing and the Effects of Aggregate Demand on Economic Activity", Journal of Political Economy, 100, 1153-1207.

Rotemberg J. and M. Woodford (1993), "Dynamic General Equilibrium Models with Imperfectly Competitive Product Markets", mimeo MIT and University of Chicago.

Sneessens H.R. (1987), "Investment and the Inflation-Unemployment Tradeoff in a Macroeconomic Rationing Model with Monopolistic Competition", European Economic Review, 31:781-815. 